\title{
Ocupación de fronteras: los proyectos poblacionales entre el Cauca y Antioquia después de la era federal ${ }^{*}$
}

\author{
Por Wilder Andrés Carrero*
}

\begin{abstract}
Resumen
Al terminar la era federal (1886), la ocupación del territorio colombiano era casi que incipiente; las selvas internas hacían de las ciudades y pueblos unos archipiélagos distantes los unos de los otros, conllevando a que los costos de movilidad para mercancías y demás productos del comercio incrementaran sus precios reales, esto sin contar con los efectos que generaban las guerras civiles de carácter local y nacional. Sin embargo, como resultado de la crisis minera y el nuevo ambiente fomentado por el gobierno conservador del 86, entre el Cauca y Antioquia se proyectaron diversas empresas colonizadoras encargadas de poblar la zona y modificar el territorio; dentro de las empresas más relevantes se destacó la Empresa Burila que no solo logró contribuir con la dirección y poblamiento en la zona, sino que también alcanzó a establecer proyectos a gran escala de ocupación con extranjeros. Aunque por diversas razones de orden político y económico el proyecto no se logró concretar, es de resaltar la capacidad empresarial de los gerentes y la manera como la legislación nacional contribuyó a la legitimación de éstos.
\end{abstract}

Palabras claves: fronteras, federalismo, colonización, territorio.

\begin{abstract}
After the federal age (1886), the occupation of Colombia was almost incipient, the forests were inside the cities and towns around islands distant from each other, leading to mobility costs for goods and other products trade will increase real prices, that without the effects of civil wars generated local and national. However, as a result of the mining crisis and the new environment fostered by the conservative government of 86 , between the Cauca and Antioquia were projected several companies responsible for people colonizing the area and change the territory in the most important companies highlighted the Burila company who not only managed to contribute to the management and settlement in the area, but also managed to establish large-scale projects with foreign occupation. Although for various reasons of political and economic order the project is not managed to make, is to highlight entrepreneurship of managers and how the legislation contributed to the legitimacy of these projects.
\end{abstract}

Keywords: borders, federalism, colonization, territory.

\section{Introducción}

\footnotetext{
Artículo Tipo 2: de reflexión según Colciencias. Hace parte del proyecto de investigación "Los conflictos militares entre los Estados de Cauca y Antioquia en el marco de la Federación, una mirada desde la historia económica regional (1849 - 1886)", inscrito en la convocatoria de investigación interna de la Vicerrectoría de Investigaciones de la Universidad del Valle.

*** Historiador de la Universidad del Valle; Estudiante Maestría en Sociología, Universidad del Valle; docente hora cátedra Programa de Historia, Universidad del Cauca. E-mail: ancade23@hotmail.com
} 
Por su condición geográfica, Colombia ha sido un país con múltiples intentos de desarrollo vial y poblacional, sin embargo los altos costos de inversión y el difícil acceso a muchas de las zonas que se comprenden en el mapa político han contribuido a que el desarrollo, la cohesión interna y la consolidación del poder central en las periferias sea un proceso lento, costoso y difícil ${ }^{1}$ (Revista Semana, Sábado 10 de 2010). Dicen Safford y Palacios (2004, p. 478) que "de 760 distritos municipales de los Estados Unidos de Colombia (sin incluir Panamá), solo 21 tenían más de 10.000 habitantes en 1870. La estadística de 1876 apuntó que "la población civilizada de la República es de 2.951.323 habitantes, conforme al censo de 1870 ... Los aborígenes salvajes que ninguna relación tienen con los hombres civilizados, pueden estimarse en 80.000". Adelante añadió que en los 1.331 .000 kilómetros cuadrados de la República, "con mediano cultivo podrían vivir y prosperar más de cincuenta millones de habitantes".

Sin embargo, con todas las críticas positivas o negativas que se le pueda hacer a dichos intentos, es obligatorio reconocer que a través de nuestra historia republicana, diversos gobiernos se han interesado, unos más que otros claro está, en ocupar y desarrollar el mayor número de hectáreas que ocupan el mapa político, así como también llevar el control y la representación estatal a aquellos lugares donde la selva se confunde con los mitos y leyendas de viajeros, campesinos y pobladores (Serje, 2005).

Un ejemplo de esto se dio en el Quindío, dividido en dos departamentos ${ }^{2}$ que quizá al ser transitados hoy en día no den la impresión de haber sido una barrera selvática casi que inexpugnable hasta finales del siglo XIX, cuando se vivió en dicho espacio la intervención por una de las empresas políticas, económicas y sociales más impactantes de la historia del Estado colombiano, pues en menos de un siglo se logró modificar casi que completamente el paisaje dándole paso a la producción agrícola que en los años cincuenta, con el café, convirtió la zona en el motor del desarrollo económico colombiano.

Por tal motivo, se pretende en este artículo exponer uno de los proyectos empresariales iniciados en la zona a finales del siglo XIX por la Empresa de Fomento y Colonización Burila, quien con el interés y apoyo del gobierno central y local, pretendió ocupar el Quindío con migrantes franceses y demás extranjeros que quisieran llegar a dicho territorio. De antemano es importante resaltar que dicho proyecto no logró consolidarse, sin embargo el interés empresarial vinculado al proceso, así como también, la función, apoyo y estrategia asumida por el Estado para legitimar y fomentar la ocupación del territorio, es relevante en los estudios regionales.

\footnotetext{
${ }^{1}$ A pesar del intento del último gobierno de Álvaro Uribe Vélez, la situación del poder central sigue estando en tela de juicio... El gobierno se fundamentó en la búsqueda de una cohesión interna y fortalecimiento de las Instituciones, sin embargo los resultados contrastan con las promesas, pues una de las características es el incremento de la desinstitucionalización aunque no se pueda negar los logros en seguridad militar en ciertas regiones del país que se caracterizaron por el libre accionar de bandas criminales.

${ }^{2}$ Los Departamentos de Risaralda y Quindío
} 
Para tal fin, se dividirá el artículo en tres partes; la primera hará hincapié en el proyecto nacional de ocupación espacial en el Quindío, segundo se hará una breve presentación de la empresa y su intervención en el espacio y por último se presentará el cruce de correspondencia y proyección empresarial francocolombiana, los logros y los resultados finales.

Este artículo surge como uno de los resultados de la investigación "Los conflictos militares entre los Estados de Cauca y Antioquia en el marco de la Federación, una mirada desde la historia económica regional, (1849-1886)" que actualmente se está adelantando con el profesor Carlos Murgueitio, docente del Departamento de Historia de la Universidad del Valle.

\section{La ocupación del Quindío: campesinos, empresas y Estado}

Desconocer los proyectos empresariales de población del Quindío así como también la migración campesina y los programas estatales de colonización antes de la Regeneración es imposible (Bushnell, 1984, p. 177) ${ }^{3}$, sin embargo, al hacerse un examen detallado de las fechas y lugares de poblamiento se resalta que la ocupación de este territorio se consolidó después de la instauración del proyecto regenerador, que pretendía no solo desarrollar económicamente al país, sino también ejercer el control político en la mayor cantidad del territorio posible y detener la dura conflictividad de la zona que había afectado tanto las economías antioqueña y caucana. Aunque las dos siguientes guerras civiles (1875 y 1899-1902) igualmente afectaron el proyecto de poblamiento por la invasión a las haciendas, el reclutamiento forzoso y la destrucción de lo poco que se había logrado en tiempos de paz ${ }^{4}$ (Otero D'Costa, 2001, p. 65) éstas no fueron lo suficientemente fuertes para detener la locomotora modernizadora emprendida durante la Regeneración.

Para el caso del Quindío, el poblamiento determinaba la ampliación de vías que comunicaran el sur con el pacífico así como también con el oriente y el norte; de la misma manera para las regiones de oriente hacia el pacífico y demás salidas para productos alimenticios, minerales o la introducción de lujos a las cabeceras como Rionegro, Medellín, Popayán, entre otras. Inicialmente estos programas poblacionales obedecían a la ocupación de espacios pertenecientes a empresas territoriales o mineras, quienes veían en los campesinos

\footnotetext{
${ }^{3}$ Recuérdese que desde el gobierno de Santander (1821) se empezaron a crear estímulos a la colonización y la inversión extranjera.

${ }^{4}$ Un relato muy particular que puede describir este aspecto es el que hizo Enrique Otero en sus memorias de la Guerra de los Mil Días cuando recordó la historia de un combatiente liberal: "Yo me tercié el rifle y andando solamente de noche y durmiendo en la montaña en el día, emprendí la vuelta a mi casa a la cual llegué al cabo de cinco jornadas.

¡ah!, ¡no encontré nada!, ¡mi mujer muerta! Mis hijos, recogidos en la casa de un vecino compasivo. ¡Todo se lo había llevado el enemigo!: la vaca, el caballo de la trillanza, las ovejas... destruyeron los muebles, y para rematar, incendiaron la casita. Mi infeliz esposa había muerto de la pena. Solo encontré a mi perro Montalbán que me recibió aullando dolorosamente. ¡Ah!, mi pobre Montalbán. Estaba flaco; sus huesos le habían roto la piel; me batió la cola débilmente, me lamió la mano, me miró con sus ojos inteligentes de un modo raro, después, se acostó sin fuerzas bajo un corredor medio arruinado. Entré a las ruinas, todo era tristeza, abandono; por aquellos escombros vagaba el gato como una sombra, como un fantasma. Al verme, huyó apresurado y se refugió en la espesura, maullando tristemente; sentí una dura punzada en el alma y salí llorando del perdido hogar. A mi vuelta encontré a Montalbán tendido en el patio, estaba muerto".
} 
pobladores, los brazos necesarios para salir del encierro selvático que tenía el territorio construyendo vías de comunicación; así, durante la ocupación se encontraron familias caucanas que migraban hacia el Quindío para escapar de las haciendas o de las guerras civiles (Zuluaga, 2007), como también familias antioqueñas o boyacenses (Tobasuña, 2007) que buscando una mejor vida aprovechaban las leyes de baldíos que permitían poblar estos territorios.

Dado que el programa colonizador tenía un respaldo estatal fue común encontrar legislaciones que beneficiaban o protegían a los pobladores y empresarios durante la ocupación. Como se trataba en la mayoría de los casos de terrenos baldíos, el Estado tenía dos formas de repartirlos; por un lado, las tierras se podían destinar al crecimiento de la economía rural, mediante su distribución a precios mínimos entre los cultivadores que estuvieran dispuestos a laborarlas y por otro lado, los baldíos eran una fuente de ingresos para el Estado, pues resultaba más productivo vender la tierra al mejor postor que regalarla.

Durante la era federal, la región se convirtió en un espacio atractivo para migrar, no solo como lugar de escondite a los reclutamientos, sino también por las riquezas en minas de sal y la posibilidad de tener cultivos y animales ya que el gobierno apoyaba la fundación de dichos poblados aprobando escrituras y legitimando la migración. Durante la gobernación de Mariano Ospina Rodríguez en Antioquia se puede notar dicho interés colonizador pues se decía que la intensa migración hacia Comiá (Concordia), estaba motivada por la abundancia de ricas "fuentes de oro" ubicadas en los ríos que corrían al sur de dicha población, y por el propósito de los colonos de explotarlas (Vélez J, 2002). Buscando la línea quebradiza que marcaba la frontera con su vecino, el Cauca, los antioqueños pretendían avanzar hacia las poblaciones de Marmato, Supía y Riosucio, dado que allí se ubicaban las principales minas de oro y plata de la región; esto sin contar con las minas de sal que eran otra de las tantas actividades minero-comerciales que un empresario podía desarrollar a buen beneficio. Sin embargo, el Cauca siempre tuvo mayor número de brazos ocupados en la zona comparado con los antioqueños (Borrero C, 1888, p. 285).

La otra estrategia de colonización se dio con la expansión de una frontera agrícola que vinculaba directamente al Quindío; recuérdese que en el caso de Antioquia, ésta no contaba

...con una región que le permitiera abastecer plenamente de productos agrícolas a las zonas dedicadas a la minería. El área cultivada en el centro de la provincia era insuficiente para satisfacer no sólo las demandas de centros mineros como Antioquia, Zaragoza, Santa Rosa y Titiribí, sino puntos como Marmato, Supía y Quibdó, que estaban por fuera de su jurisdicción administrativa pero dentro de su órbita comercial y se encontraban relativamente alejadas. La agricultura fue entonces, una actividad que permitió la dinámica del mercado, aunque inicialmente se orientó al autoabastecimiento en los frentes de colonización (Vélez, 2002, p. 82).

El avance de colonos hacia el sur se acompañaba entonces de dos factores a favor, uno relacionado con la explotación de minas y el otro con la posibilidad 
de ubicarse en tierras pertenecientes a un empresario interesado en valorizarlas o en territorios baldíos.

El desarrollo de la agricultura a pequeña escala pero con vista a futuro fue otro aspecto interesante para la sociedad antioqueña quien lograba con esto, superar la producción minera que posteriormente caracterizó a las empresas colonizadoras" (Vélez, 2002, p. 95). Esta nueva producción vinculó cultivos como el añil, tabaco, caña, maíz, cacao, pastos, así como también la cría de cerdos y ganado muy bien pagos en el Chocó y en Cartago.

Una de las compañías que más se resaltan de esta primera oleada colonizadora es la Compañía González Salazar y Cía., la cual controlaba los territorios de la concesión Aranzazu, perteneciente a uno de los principales terratenientes de la frontera caucano - antioqueña, el señor Juan de Dios Aranzazu. Al respecto plantea James Parsons (1997) que esta compañía fue una de las que estuvo a la cabeza del poblamiento en la región (Cadena, $\mathrm{O}$, 1997), contando con las mismas características en lo referente al conflicto con los colonos que alegaban tener el derecho a ocupar la tierra que al parecer era baldía ${ }^{5}$, pero que la empresa alegaba tener derechos por escritura pública.

De las fundaciones que vincularon conflictos entre colonos y terratenientes puede decirse que hubo colonos que por su poca capacidad monetaria terminaron huyendo de la zona en busca de nuevas tierras para colonizar, pero también hubo colonos que lograron establecerse en las poblaciones. Muchos de estos se convirtieron en comerciantes o influyentes personajes de la región (Christie, 1986, p. 23-53); ahora bien, aunque en muchos casos la explotación comercial se hizo legalmente, pues el Estado reconocía la compra y legalidad de terrenos, la misma transacción comercial que se hacía con la ayuda de un representante legal, se prestaba para la especulación y el mal manejo a los linderos de las propiedades. Fue este el método utilizado por muchos empresarios territoriales para así ganarse una gran cantidad de terrenos baldíos que pertenecían al Estado.

Además de estos hechos, de la mano de la colonización llegó el alambre de púas el cual permitió incrementar el control territorial por parte de estos empresarios. Este aspecto se hizo manifiesto después de 1880 en casos como el de las haciendas caucanas de Japio, Quintero y La Bolsa donde se empezó a usar como un instrumento para absorber las pequeñas propiedades englobadas dentro de los presuntos linderos porque las mejoras encerradas dentro de otras propiedades no tenían precio. Después de la Guerra de los Mil Días se intensificó el proceso de alambrar, con las consecuencias deteriorantes de la pequeña propiedad (http://www.lablaa.org/blaavirtual/historia/latierra/libro6-4.htm)

Pero no sólo esta forma se utilizó para monopolizar los baldíos y hacerse a ellos, otra de las maneras fue la presentación de títulos mineros. Al obtener dichos títulos se podía acceder a cerca de 500 y 1000 hectáreas por concesión, para lo cual era suficiente con declarar un yacimiento y pagar el respectivo

\footnotetext{
${ }^{5}$ En el caso de esta compañía, se trata de los actuales municipios de de Salamina, Neira, Aranzazu, Filadelfia y Manizales.
} 
impuesto. Dado el desorden y poco control de los recursos y las tierras con que contaba el Estado, fue fácil hacerse a muchos terrenos. Estos casos han sido registrados en regiones como las de Huila, Caldas y norte del Cauca, donde los empresarios se valieron de estas disposiciones para reivindicar minas a menudo imaginarias y asegurarse así el control de los baldíos y bosques.

En el caso de la colonización del Quindío con pobladores del sur, es decir del Cauca, la ocupación respondió igualmente a un proceso de búsqueda de mejores tierras, ocultamiento de los reclutamientos y valorización de terrenos baldíos del Estado o tierras en concesión a empresarios y políticos caucanos. Es importante resaltar que el Cauca contaba con mayor población que Antioquia, pero la densidad demográfica era inferior y la participación en la propiedad de la tierra no alcanzaba los índices registrados por los antioqueños ${ }^{6}$. Como lo muestran Frank Safford y Marco Palacios (2002, p. 320 ), para 1870 , la población antioqueña era de 365.900 personas, la Caucana registraba 435.078 personas pero la densidad demográfica era para Antioquia del 11,1 y para el Cauca del 6,9; al mirar la apropiación de las tierras se puede registrar un mayor número de propietarios en el Cauca que en Antioquia, pero por su extensión, un número de $603.800 \mathrm{~km}^{2}$ de áreas baldías en el Cauca, frente a $26.000 \mathrm{Km}^{2}$, en Antioquia.

Como un agregado, la expansión antioqueña hacia diversas zonas inicialmente con el oro y la ganadería como motor y posteriormente con el interés colonizador inicialmente agrario, le permitió establecer poblaciones que si bien en un inicio no fueron muy relevantes, al cabo de poco tiempo se convirtieron en lugares de avanzada colonizadora, venta de productos para el abastecimiento alimenticio y textiles de las principales ciudades, etc., con una particularidad: la relativa cercanía de unas con otras; para el caso del Cauca, la población era algo así como una Oceanía, un archipiélago de islas minúsculas que se perdían en el ancho territorio y que la selva y mosquitos devoraban lentamente.

En los viajes hechos por Fr. Von Schenck (1880), refiriéndose al Valle del Cauca decía que:

En la época de lluvias, durante semanas es imposible o por lo menos peligroso viajar por aquí, en la época de verano sólo con mucho cuidado se pueden cruzar las casi secas zanjas cuya superficie está cubierta con un delgado manto de yerbas engañosas, ya que debajo de él se encuentran una arcilla pegajosa de grueso espesor, en la cual se hunden los caballos hasta el pecho; solamente a costa de mucho trabajo y tiempo se pueden sacar de aquí. Los anchos ríos La Onda, El Mico y La Paila, que por esta época están casi completamente secos, exigen en tiempos de lluvias numerosas víctimas. (Entre Cartago y Tuluá no existe un solo puente). Adelante de Bugalagrande se extiende en muchas millas el monte Murillo, un conjunto de bosque, monte y pajonal de muy mala fama,

\footnotetext{
${ }^{6}$ El crecimiento demográfico de Antioquia entre 1835 y 1898 era del 2,18\% frente al del Cauca que era el segundo mayor crecimiento demográfico de los Estados Soberanos con un 2,14\%. Parece ser, según Kalmanovitz que ambos Estados contaron con mejores condiciones de salubridad, educación y nutrición que los otros 7 Estados. (Kalmanovitz, 2010: 101)
} 
debida a la inseguridad provocada por los ladrones negros. El asesinato y robo de una posta del correo que vino a caballo de Buga a Cartago todavía estaba fresco en la memoria de todos, y la agitada fantasía de mis sirvientes calificó a dos negros con los cuales nos encontrábamos, como bandoleros, lo que hizo que nuestra pequeña caravana se juntara y tomara todas las medidas de precaución, que desde luego eran innecesarias. Fue esta la única región de Colombia donde oí hablar seriamente de inseguridad en los caminos (en tiempos de paz) (1953, p. 54-55).

A pesar que habían diversos asentamientos en la vía, ninguno de éstos era de gran importancia, algunos se caracterizaban por servir de pernotaje (caso Cali - Palmira) y otros con una minúscula importancia, se erigían como caseríos, como el caso de poblaciones como Cartago, Buga, Popayán (por ser capital), Pasto, Ipiales o Buenaventura; pero en medio de estas poblaciones y cada vez más hacia el sur, la miseria se registraba en las casuchas de paja y un perro famélico que acompañaba su entrada.

A diferencia de Antioquia, el Cauca no tenía un producto que garantizara la movilización de brazos para la producción o colonización y el único producto capaz de hacer esto en el siglo XIX era el oro, mineral que se producía en las minas fronterizas y que por lo tanto los resultados de su explotación quedaban en las tiendas de los antioqueños. Aún así, la pujanza de algunos políticos y empresarios caucanos se empezó a manifestar con intentos pequeños pero relevantes en la historia de la provincia.

Estos personajes muy característicos a mediados de siglo (Safford, 1977), concluían que un primer factor clave en la explicación del atraso caucano, al igual que en el resto del país, radicaba básicamente el su aislamiento geográfico y la mala condición en los caminos. Este aspecto fue descrito no solo por viajeros como Von Shenk sino también por personajes como Phanor Eder, biógrafo del Cónsul norteamericano, James Eder.

Y es que "el principal problema que debieron afrontar los caucanos consistió en que el Cauca estaba completamente aislado del resto de la Unión por la cordillera Central y del mar Pacífico por la Occidental. Así, paradójicamente, la Cordillera de los Andes, que permitía la conformación de los nichos ecológicos de los altiplanos, de los valles profundos o de los piedemontes, era a su vez, el principal obstáculo a su desarrollo, pues al dificultar el comercio no permitía que se canalizaran las energías hacia actividades realmente productivas desde el punto de vista capitalista o que facilitaran el desarrollo económico. Desde esta perspectiva lo más apremiante era vencer las dificultades en las comunicaciones internas y externas" (Valencia, 1993, p 95). Por tal motivo, esta problemática se enfrentó de tres maneras, primero, conservando los caminos ya construidos y abriendo nuevos con la mano de obra de presidiarios; segundo, utilizando las rentas municipales en lo que se denominó como trabajo personal subsidiado (Valencia, A, 1993, p 95); y tercero, adjudicando contratos a compañías y empresarios interesados en dicha tarea.

El Cauca inicialmente contaba con pocos caminos que permitían comunicar al Estado con el mar, con el occidente (Tolima y Cundinamarca) y con Antioquia. 
Básicamente se trataba de Caminos del Estado y Caminos Nacionales, los primeros que pueden limitarse a dos, iniciando en Ipiales hasta Cali, caminando hacia el norte para buscar el Camino del Quindío y el segundo desde Cali por el piedemonte cordillerano del occidente buscando la salida hacia las minas de Supía y Marmato y claro está, de esta forma llegando a Antioquia; en lo referente a los Caminos Nacionales, únicos en los que el Estado central intervenía, existía uno saliendo de Cali hacia Buenaventura y otro que hacía la ruta Túquerres- Barbacoas-río Tumaco y posteriormente al mar. Sin embargo, los continuos levantamientos y guerras civiles impedían la consolidación o adecuación de estas vías.

El gobierno del Estado consideraba que la punta de lanza que debía abrir los caminos era el tren, seguido de los vapores y como último los caminos de herradura, sin embargo el fisco no alcanzaba ${ }^{7}$ para tales planes, dados los continuos azotes de las guerras civiles y las entradas económicas con que se contaba; por tal motivo la mejor alternativa era la tercera vía, es decir, encargando principalmente a empresarios privados las labores de apertura de caminos, como ocurrió en 1858 cuando "se le concedió privilegio al señor Camilo González para que reparara la vía del Guanacas que comunicaba con el Tolima y en enero de 1860 [cuando se le concedió el] privilegio a Ramón E. Palau para abrir un camino de herradura que comunicara a Cartago con Cundinamarca, por el paso del Quindío, lo que lo convirtió en un importante empresario territorial de la zona. Igualmente, en 1860 se otorgó privilegio para construir barcas movidas por cables en los pasos de los ríos Cauca y Darién" (Valencia, A, 1993, p 105).

A diferencia del caso antioqueño, en el Cauca los caminos no se construyeron de la mano de los poblamientos, al pretenderse más bien comunicar internamente el archipiélago poblacional que ya existía, aunque hubo casos como el de la construcción del tren hacia Buenaventura donde sí se lograron crear unos cuantos caseríos por parte de los trabajadores o casos como el del proyecto empresarial de la familia Reyes hacia el Caquetá, el cual permitió el establecimiento de algunas poblaciones de paso, como también poblaciones que posteriormente se convirtieron en enclaves económicos como Puerto Asís, actual capital económica del departamento del Putumayo.

Ahora bien, ¿por qué invertir en el Cauca? Si bien es cierto, parecieran no ser muy rentables dichas empresas, los resultados en cuanto adjudicación de baldíos justificaban el hacerse acreedor de una concesión y por lo tanto terminar incrementando el poder territorial de algunas empresas o familias, aspecto denunciado por Peregrino Santacoloma en 1872, cuando en su función como Secretario de Gobierno descubrió que el Estado del Cauca había distribuido de forma corrupta un sinnúmero de baldíos que terminaron por

\footnotetext{
${ }^{7}$ Recuérdese que durante la Federación, la carga de las obras públicas recayó en los fiscos locales y no nacionales exceptuando el caso de vías de carácter nacional.

${ }^{8}$ En el capítulo IV, Alonso Valencia logra hacer una extensa y detallada aclaración de los caminos que se abrieron a licitación o se terminaron, los cuales pretendían sacar del encierro al extenso Estado del Cauca. Sin embargo la practicidad, experticia de sus ingenieros y conflictos internos determinaron la terminación inconclusa de los mismos.
} 
hacerle perder el control de la colonización al gobierno regional (Valencia, 1993, p 59-62).

Sin embargo, a pesar de los actos de corrupción en torno a la adjudicación de baldíos y las innumerables hectáreas apropiadas ilegalmente durante la consolidación de los proyectos empresariales, algunas fronteras como la del Quindío, lograron una ocupación y transformación del espacio geográfico de una manera tajante. ¿Cuál fue el éxito de esta frontera si se comparara con las otras $^{9}$ ?

Es claro que el Cauca no contaba con mucha gente para poblar todo el territorio que detentaba, así que el poblamiento de algunas fronteras se hacía de mayor relevancia que en otras; recuérdese entonces que Antioquia era el vecino de mayor importancia comercial y política que tenía el Cauca y por lo tanto, controlar el espacio fronterizo para ambos gobiernos era relevante. En el caso antioqueño el poblamiento fue orientado por la construcción de caminos, la explotación de minas y la formación de una pequeña masa de campesinos libres y en algunos casos, pequeños propietarios. Pero para los caucanos, la colonización de la frontera estuvo orientada por dos métodos: el primero que consistía en poblar con vagos y delincuentes en lo que se conoció como la Colonia penitencial de Boquía en el Quindío y la segunda fue atrayendo pobladores de otros Estados como ocurrió con los antioqueños quienes recibían, después de vivir seis meses en el Cauca, la ciudadanía y la propiedad de los lotes que beneficiaran.

Entrada la Regeneración, fueron diversos los Decretos hechos por el gobierno central o por las autoridades locales, pretendiendo ejercer un mayor control sobre las ocupaciones y las empresas de colonización que habían empezado a presentar una diversidad de conflictos con los campesinos colonizadores y algunas autoridades. Un ejemplo de esto se dio durante la administración de Juan de Dios Ulloa quien como Gobernador del Cauca impulsó el Decreto \# 20 de 7 de octubre de 1887, por el cual se reglamentaba la inmigración y colonización de los terrenos del Departamento y se prohibía la destrucción de las plantas útiles como cauchos, quinas y maderas preciosas (AGN, $F$. Mingobierno, Sección República, f, 054).

En dicho acuerdo se resaltan varios aspectos tales como: 1) la posición del gobierno frente a los resguardos, los cuales en el artículo 10 se protegían de ocupación y usurpación siendo defendidos por

[...] los Fiscales del Circuito y los Personeros Municipales. Para tal efecto, dichos empleados harán constantemente las pesquisas y averiguaciones del caso, procediendo sin demora ni miramiento alguno á ejercer la defensa que se les ordena, y á la que están obligados por las leyes sobre protección especial otorgada á los estados resguardos (AGN, F. Mingobierno, Sección República, f, 054).

\footnotetext{
9 Además de las fronteras externas como la del Quindío que separaba al Cauca de Antioquia, existían unas fronteras internas como el caso del Pacífico, las fronteras de indios en el actual Cauca, Huila y Tolima y fronteras como las del Caquetá o el Amazonas, esto sin contar las fronteras internacionales como las del Perú, Ecuador o Brasil.
} 
2) las estrategias de control migratorio, el cual en los artículos 1 y 2 de dicho decreto especifican que para poder ocupar un terreno en una provincia, los migrantes se debían presentar

[...] ante el respectivo Prefecto de la Provincia provisto de una certificación expedida por el Prefecto de la Provincia de donde hubiese sido últimamente vecino, ó del Ministro ó Cónsul General de Colombia, si es extranjero, en la cual constara que no tiene causa pendiente en el país donde haya residido. Este certificado será autenticado por el Ministro de Relaciones Exteriores si el inmigrante es extranjero o del Gobernador del Departamento si es colombiano (AGN, F. Mingobierno, Sección República, f, 054)

Después de haber seguido estos pasos,

el Prefecto Provincial que recibe la expresada certificación, la examinará y numerará; registrándola enseguida en un libro especial con el mismo número de la certificación y asentará en él el nombre del inmigrante y el de cada uno de los miembros de su familia, si la tiene ó quien le señalará el Distrito donde quiera avecindarse y del que no podrá cambiar de vecindad sin permiso del mismo Prefecto que otorgó el señalamiento expresado" (AGN, F. Mingobierno, Sección República, f, 054)

3) la distribución del poder delegando órdenes a las provincias y sus representantes, quienes serían los garantes de la protección de los bienes materiales del Estado como las maderas, las riberas de los ríos La Vieja y Quindío, la propiedad privada, etc., teniendo los alcaldes la potestad de hacer efectivas las prohibiciones

condenando a los contraventores con una multa de cinco pesos por cada árbol destruido ó con pena subsidiaria de un día de prisión por cada peso de multa. La reincidencia se castigará con ciento ochenta pesos $(\$ 180)$ de multa. [lgualmente si se poblaba territorio no autorizado por el gobierno] por consiguiente, [no obtendría de ellos], en ningún caso, adjudicación legal y será lanzado de ellos cuando el Gobierno lo disponga, sin derecho a indemnización por mejoras (AGN, F. Mingobierno, Sección República, f, 054).

Y 4) La pretensión del Estado por controlar el crecimiento poblacional en sus territorios, por lo cual en el artículo 5 se determinó que...

Los Prefectos Provinciales ordenarán y harán por sí, que en su respectiva Provincia se levante un censo ó padrón de todos los que ocupan los terrenos baldíos en el cual se expresará el nombre del lugar que ocupan y el de su residencia, con determinación del Distrito, á fin de saber donde deben hallarse en caso de alguna requisitoria judicial ó de la investigación de algún delito. Igualmente anotarán si el ocupante de un lugar posee medios de subsistencia ó es vago y díscolo (AGN, F. Mingobierno, Sección República, f, 054)

De todas maneras, ejercer un control total fue una tarea casi que imposible pues comúnmente, las autoridades encargadas no estaban en la capacidad de 
ejecutar dichas normas por sus vinculaciones a las empresas (como se verá con el caso de Burila), su desconocimiento de agrimensura, etc.

\section{La intervención en el espacio quindiano... Burila como empresa colonizadora}

La empresa de Fomento y Colonización Burila se fundó en pleno inicio de la Regeneración; el país estrenaba constitución y los accionistas de dicha empresa en muchos casos eran políticos reconocidos en el país como la familia Reyes (Cadena, 1998, anexos); de todas maneras, a pesar del éxito económico y político logrado por la empresa, desde antes de su fundación hasta los años treinta del siglo $X X$, la particularidad fue que se viera envuelta en una diversidad de conflictos judiciales o hasta de ataques contra la integridad de algunos accionistas o representantes de la misma (Carrero, 2008).

La idea de fundar una empresa de colonización no era nueva para su principal accionista y fundador, el señor Lisandro Caicedo pues éste desde mucho antes se había iniciado en un proyecto de la misma índole. El primer proyecto empresarial que le permitió conocer sobre las estrategias, rentabilidad y posibilidades de triunfo en proyectos de colonización lo logró de la mano del norteamericano David R. Smith, con quien fundó la compañía de Fomento La Paila (Londoño, 2003, p, 441), en los terrenos heredados en 1845 luego de la muerte de su padre, José María Caicedo y Zorrilla. Posteriormente, después de la disolución de esta compañía se asoció con los Uribe (Tomás Uribe Toro y su hijo Julián) y el 24 de octubre de 1877 fundaron una segunda compañía de colonización que duró cuatro años. Durante este tiempo, Lisandro Caicedo asumió "directamente" la explotación de esta propiedad y sus esfuerzos se concentraron en mejorar su productividad y en poblar sus zonas periféricas" (Londoño, 2003, p, 422).

Aunque Caicedo tenía suficientes habilidades para desempeñarse en este tipo de negocios, no pudo explotar todas las tierras que había obtenido y las tuvo que dividir en cinco partes (Londoño, 2003, p, 420-425) ${ }^{10}$, de las cuales solo había alcanzado a explotar lo perteneciente a la zona plana de la hacienda. La venta de las tierras contiguas al río Cauca solamente se realizó de una manera esporádica, por lo que no se logró cumplir todo el objetivo, quedándose con algunas tierras que no tenía sentido cultivar.

Otro factor que aquejó a Lisandro Caicedo fue la dinámica colonizadora que había llegado al Quindío y que poco a poco penetraba sus tierras de la zona montañosa, dado que ningún colono estaría dispuesto a pagar por las tierras que consideraban como vírgenes y baldías. Al darse cuenta de la gravedad del problema y dado el desarrollo que tuvo la Compañía de Fomento la Paila,

\footnotetext{
${ }^{10}$ La hacienda se podía dividir de Norte a Sur así: El medio, La Paila, EL Guavito y Morillo y de Este a Oeste: Burila (zona montañosa) hasta el río Cauca. La hacienda fue valorada en \$60.000, las acciones que integraban esta propiedad fueron tasadas de la siguiente manera: Burila \$20.000, el medio \$14.000 y La Paila \$26.000. La mitad de estos terrenos fueron vendidos a Smith en \$30.000, pagaderos de contado de $\$ 2.000$, los $\$ 28.000$ restantes se cancelarían en anualidades de $\$ 2.000$.
} 
Lisandro Caicedo centró todo su interés en la zona alta o montañosa de Burila, terrenos de su propiedad según la división realizada de común acuerdo con los miembros de su familia en 1868. Desplazarse a la zona montañosa era la última alternativa que tenía para llevar completamente adelante sus proyectos empresariales y esto sólo se lograba si podía vincularse al mercado de tierras abierto por el proceso de poblamiento en el Quindío.

Con el interés de solucionar pronto su situación como empresario y teniendo presente el Decreto \# 20 del 7 de octubre de 1887, específicamente el artículo 8 (AGN, F. Mingobierno, Sección República, f, 054) que obligaba a todo el que poseyera baldíos con títulos en el Departamento del Cauca, registrarlos ante las autoridades para que estas por medio de un agrimensor hiciera las respectivas verificaciones, Lisandro Caicedo tuvo que esperar a que el Gobernador del Cauca logara la aprobación de parte del Procurador General de la Nación en lo relacionado con la aclaración de los linderos.

En la petición hecha por la Gobernación al Procurador se hacía especial ahínco en la necesidad de que se pudiera conocer hasta dónde alcanzaban los derechos de señor Caicedo, para así poder negar o darle la protección correspondiente sobre territorios ocupados ilegalmente y legitimar la fundación y accionar de la empresa; igualmente se hacía relación a la tenencia de las salinas (AGN, F. Mingobierno, Sección República, f, 054). Como un resultado de dicha petición, se le encomendó a un agrimensor la revisión correspondiente de los linderos; pero por los continuos conflictos que se siguieron presentando no se estableció claridad sobre los límites de la empresa.

Los conflictos más relevantes que tuvo que afrontar la empresa se centraron en los valles del Río la Vieja, así como también con poblaciones como la actual Sevilla en el norte del Valle y algunas ciudades como Calarcá, hasta la intervención de la misma durante la administración liberal de Enrique Olaya Herrera en 1930 (Cadena, 1998).

\section{El programa colonizador de Burila y los acercamientos con los franceses}

Como un proyecto innovador en la región, Marcelino Arango (1886), Gerente representante de la Empresa Burila presentó a la Junta de Accionistas la posibilidad de emprender un proyecto colonizador con migrantes franceses, sin embargo la zona presentaba una diversidad de problemas, específicamente los creados por la migración de campesinos al territorio sin un arreglo previo con la empresa. De todas maneras, dicha migración había permitido desnudar riquezas mineras y generosidad en la fertilidad de la tierra, aspecto clave para fomentar con mayor razón la colonización dirigida.

En vista que el conocimiento sobre dichas tierras era popular, los agentes y el gerente de la compañía siempre estuvieron al tanto del desarrollo de la colonización y los hallazgos de minas dentro de Burila; por tal motivo, aprovechando la valorización y que sus principales accionistas eran representantes del proyecto regenerador, el gerente de la compañía empezó a ver con buenos ojos la idea de fomentar la venta de acciones a empresarios nacionales y extranjeros. 
En el informe comentado, el gerente recalcaba que:

Con ocasión del descubrimiento de ricos sepulcros en el dilatado valle de La Vieja hoy está llamando la atención de los empresarios mineros del país ese privilegiado suelo; la riqueza de los sepulcros denuncia la existencia de minas.

Sensible es que especulaciones de este género -las únicas que se pueden poner en armonía perfecta y fecundada pequeños y opuestos intereses en la síntesis de un fin común grandioso- no sean estudiadas ni comprendidas por nuestros hombres de negocios; refractario generalmente a todo adelanto que puede con sus inveterados hábitos de rutina ó con una sindéresis formada en nuestro alejamiento de todo comercio civilizado que nos hace pesimistas, sino intolerantes con cuanto diga relación con cosas nuevas ó no vistas dentro de la esfera de las vulgares ó comunes apreciaciones. Más los que tanto por patriotismo como por cálculo pretendemos llevar adelante una empresa como esta tenemos confianza en que su desarrollo y resultados serán norma de una especulación industrial desconocida y estímulo eficaz para los que en pos de nosotros se propongan avanzar por los mismos caminos.

Es factible que el Gobierno Nacional cuando se penetre de espíritu y de tendencias de esta empresa de colonización, explotación y fomento quiera patrocinarla y ampararla como especulación de interés general de grande trascendencia por cuanto su esfera de acción no se concreta a las tierras de Burila solamente sino que en su desarrollo natural y lógico irá dilatándose mediante adquisiciones sucesivas de tierras de particulares o baldías al sur de nuestros desconocidos Andes Centrales ricos en todos los dones de una naturaleza pródiga y fecunda; cuando especulaciones de menos interés público han obtenido el favor y la liberalidad oficiales (Archivo Histórico de Cartago, (AHC) Fondo Judicial, Serie Demandas, Fol. 92, p. 72.).

La vinculación de personajes de la vida política del país como accionistas de la empresa había permitido solidificar las bases legales de la misma. Dicho respaldo durante el proyecto regenerador permitía que la empresa tuviera un desempeño preponderante, pues los proyectos colonizadores estarían dirigidos siempre hacia el bien de la nación y del programa de gobierno.

Dentro de los proyectos regeneradores se encontraba la unión por medio de vías de una nación fragmentada en pequeños Estados independientes. Dado que la capacidad adquisitiva en un país que salía de una guerra e iniciaba otra era un tanto difícil, la opción de mirar al extranjero para fomentar colonizaciones y atraer inversiones siempre estuvo latente.

Al igual que en países como Venezuela, Brasil, México, Guatemala, entre otros, se consideró al elemento extranjero como sinónimo de progreso, para los accionistas de Burila, la vinculación con extranjeros era una opción muy importante en la construcción su proyecto empresarial.

En el mismo informe presentado por Marcelino Arango a la junta de la compañía, decía que: 
Juzgo de oportunidad indicaros que sería prudente y provechoso reservar un número considerable de acciones no menor de 300 para brindarlas en el extranjero. Esta indicación tiene su fundamento en el conocimiento de referencias dignas de crédito, relacionadas con esta especulación dadas a conocer por un accionista amigo nuestro en un viaje reciente y tal asenso doy a dichas referencias y tanta importancia al incidente que me permito suplicaros que autoriceis al Gerente para hacer las gestiones que crea conducentes al objeto; alentándome al pediros esta autorización la probabilidad de buen suceso así como el común anhelo de atraer a nuestro país, aunque en pequeña escala, por ahora, el elemento extranjero industrioso y de trabajo en condiciones preparadas y propicias para una formal colonización y para exportaciones de índole complexa apreciables sin dificultad por el criterio especulativo (AHC, Fondo Judicial, Serie Demandas, Fol.92, p. 72).

A lo que la asamblea votó diciendo:

Queda el Gerente autorizado para celebrar todo convenio, arreglo, negocio o transacción que juzgue conveniente a los intereses de la empresa concorde con las indicaciones del informe y de la aprobación que les ha impartido la asamblea. Entre las autorizaciones que les confiere figura en primer término la de gestionar y entrar en arreglo para lograr la colocación de acciones en el extranjero de conformidad con su solicitud. Del uso que hiciere de esta autorización y el resultado de las gestiones dará cuenta el consejo administrativo (AHC, Fondo Judicial, Serie Demandas, Fol. 92, p. 72).

Con la concesión de poderes que había dado la asamblea al gerente, solo se había obtenido una propuesta de compra-venta por parte del señor Dr. Santiago M. Eder, por la cantidad de $\$ 64.000$. Durante esos mismos días se encontraba en el país una comisión francesa encargada de llevar a cabo la construcción del Ferrocarril del Pacífico y en su representación el Conde de Goussencourt, personaje importante para el desarrollo del proyecto extranjero de Burila. Dicho conde era accionista de una empresa de inmigración por lo que se vio interesado en constituir una compañía de colonización extranjera con capital suficiente que no sería menor de $\$ 5.000 .000$.

Lisandro Caicedo estuvo siempre al frente de las negociaciones y fue quien, junto al Conde de Goussencourt, coordinó el proyecto colombo-francés de colonización; el 20 de julio de 1886, con una visita del Conde al señor Caicedo y una serie de correspondencias se iniciaron los contactos.

En la primera misiva enviada desde Cali al Conde de Goussencourt, Lisandro Caicedo planteaba el anhelo de llegar a unos términos aceptables y precisos que sirvieran como base para la constitución de la compañía en Londres o París con capital suficiente para colonizar y explotar las tierras de Burila proponiendo:

1․ Capital social 2.000.000 de francos, dividido en 20.000 acciones de valor 100 francos cada uno y pagaderos en quintas partes por trimestres adelantados, ó en cualquiera otra forma conducente al mismo resultado. $2^{\circ}$ La compañía constituida en Manizales en 1884 se tendrá como incorporada con su capital propio de $\$ 150.000$ ó sean 750.000 francos, 
representado en el valor de las 128.000 hectáreas que mide aproximadamente el territorio de Burila, de su propiedad; y por el aval capital recibirá 7.500 acciones al portador de 100 francos cada uno.

3ํ Para la constitución de la Compañía en Londres o París, se entenderán fijadas las bases ó Estatutos más conformes con la índole de esta colonización y de las explotaciones que van á emprenderse" (AHC, Fondo Judicial, Serie Demandas, Fol. 92, p. 72)

Si el Sr. Conde de Goussencourt encontrare aceptables, sustancialmente, estas indicaciones, yo, en mi calidad de apoderado general de la compañía y especial del Sr. D. Belisario Caycedo, mi hermano, y tenedor además de un número de acciones cercano á la mitad, contraígo el compromiso de disponer los ánimos de los accionistas nacionales en el sentido de la incorporación. Y acordado que sea definitivamente el asunto por quien deba resolverlo, la denominada "Empresa Burila" procederá, previo aviso, á su disolución y liquidación en breve término (AHC, Fondo Judicial, Serie Demandas, Fol. 92, p. 72).

Interesado en el proyecto colonizador, debería lograr atraer el interés del Conde, por lo cual dirigió una carta donde decía lo siguiente:

Para que el Sr. Conde pueda apreciar mejor las condiciones del territorio que se pretende colonizar, haré anotar:

1. Que a dos leguas del camino nacional que pasa por la Paila, y por donde seguramente será construida la vía férrea proyectada, se encuentra el lindero occidental de los terrenos de Burila; siendo de observar que se puede, sin grave dificultad construir un buen camino casi plano, y llevarlo por en medio de los terrenos ya sea á Salento ó al Tolima por Anaime.

2. Que dichos terrenos no pueden ser considerados como, ó equiparados a baldíos, por haber sido en gran parte explotados, estar cruzados por veredas en varias direcciones y tener habitaciones y cultivos cercanos, así al Oriente, como al Occidente y al Norte; y

3. Que aparte de la salubridad de su clima y la feracidad de su suelo para cultivos intertropicales de todo género - cacao, café, maíz, pastos, trigo, etc, etc, existen fuentes de agua salada en gran número y minas descubiertas de evidente riqueza, que constituyen por sí solas un valor apreciable, mucho mayor actualmente que el de las tierras de cultivo (AHC, Fondo Judicial, Serie Demandas, Folio: 92, p. 72).

Posteriormente, le recordó al Sr. Conde que debía servirse decir si encontraba factible el negocio y lo que más juzgare conducente al intento, para de esta forma poder comunicarlo a los interesados en cuyo nombre gestionaba.

Luego del fracaso con la construcción del Ferrocarril del Pacífico, el Conde decidió partir nuevamente hacia Francia y mientras abordaba el barco recibió otra carta para fijar el capital y aclarar varios puntos. Se suponía entonces que el capital no podría ser menos de $\$ 5.000 .000$ y en cuanto al valor de los terrenos, quedaban en voluntad del señor Caicedo recibirlos en dinero o en títulos de la nueva compañía.

Según el capitán del barco que transportaba al señor Conde, existía en Londres 
Una poderosa compañía destinada a la migración extranjera y a la colonización de países americanos y ya [había] despachado inmigrantes y fundado colonias en Brasil y México y recientemente en Guatemala. Es Gerente de esta compañía "Le Conte de Montrueal, 21 Austin Friors, E.C. London", el Sr. Conde de Goussencourt le representa y a su nombre gestiona. En Bogotá es de ya agente el Sr. Bonnet (AHC, Fondo Judicial, Serie Demandas, Fol.92, p. 72).

Hasta dicho momento, Lisandro Caicedo guardaba las esperanzas de llevar a cabo las condiciones apuntadas. Para él, el gobierno nacional estaría dispuesto a destinar hectáreas que se abrirían paso con la colonización y en la misma correspondencia insistía que la zona propuesta para colonizar tenía:

Riquezas de todo género, hoy, en parte, disputadas sin provecho y daño para los intereses nacionales por unos pocos pobladores, de precedentes dudosos entre quienes no faltarán algunos requeridos por la función de la ley ó escapados de la justicia penal; habiendo podido observar en ellos una mal disimulada tendencia a alejar ó repeler el elemento sano e industrioso de los pueblos más cercanos del Cauca, Antioquia y Tolima que se sienten atraídos por la riqueza de esta rica región y parecen llamados a estrechar vínculos sociales - de tiempo atrás flojos o relajados, y a confundir allí mediante la confraternidad del trabajo honrado sus destinos y su suerte (AHC, Fondo Judicial, Serie Demandas, Fol. 92, p. 72).

Posteriormente Lisandro Caicedo recibió la contestación por parte del Conde de Goussencourt donde planteaba su consideración con

Dos millones de francos insuficiente para llevar á buen efecto la empresa de U., en atención, sobre todo, á las dificultades de transporte de los inmigrantes. Después de estudio en Europa le pediré á U. Que determine este capital.

Pido á U. término hasta el $1^{\circ}$ de Enero de 1888 para constituir una Sociedad de emigración. Atendida la propuesta de U. le será entregado un capita de 150.000 fuertes, ó acciones que representen este valor. Tan pronto como yo haya fijado los términos de la empresa lo avisaré a U. por cablegrama. Queda entendido que $U$. trasmite a la Compañía la propiedad de las 128.000 hectáreas con lo que pueda contenerse en ellas, es decir, minas (AHC, Fondo Judicial, Serie Demandas, Fol. 92, p. 72).

Después de recibir dicha carta enviada desde París, Lisandro Caicedo hizo los correspondientes actos de cierre y contestó la correspondencia aprobando la observación hecha sobre la insuficiencia de dos millones de francos. Lisandro Caicedo pretendía el valor en pesos en vez de francos y más teniendo en cuenta la índole expansiva que tenía la empresa junto a la necesidad de colonización extranjera planteada por el gobierno nacional en actos oficiales y propuestas solemnes de patrocinio y amparo.

Existen varias razones para que el proyecto fracasara, entre las cuales se pueden resaltar dos. La primera relacionada con la salida del Conde de Goussencourt por darse como clausurado el contrato de la construcción del Ferrocarril, y la segunda por la misiva enviada desde Bogotá a Cali en septiembre de 1886 donde se decía que: 
El conde de Goussencourt es persona distinguida; pero no es capitalista, él ha figurado únicamente como agente de la compañía. El señor Gaulmin es ingeniero muy honorable, que goza aquí de la confianza de compañías que lo han encargado en los últimos años de trabajos importantes de Ferrocarriles, en el Brasil; pero parece que su fortuna es moderada (AHC, Fondo Judicial, Serie Demandas, Folio: 92, p. 72).

A pesar de los mencionados conflictos y las diversas dificultades que tuvo que afrontar la empresa durante su tiempo de existencia, es importante resaltar algunos programas de colonización que no se logaron efectuar por diversas situaciones que de manera hipotética, dada la falta de información recolectada, se pueden plantear; entre dichos factores están los constantes conflictos que terminaron en Guerra civil o levantamientos, las dificultades geográficas, la falta de vías de comunicación que garantizaran el buen desarrollo de proyectos agrícolas o industriales, la radicalidad religiosa (teniendo presente que el proyecto que se expondrá vincularía extranjeros), la ambigüedad de los límites que generaban conflictos con campesinos, entre otros.

\section{Referencias bibliográficas \\ Fuentes documentales}

Fondo Minigobierno, Sección República. (fol. 054) Bogotá: Archivo General de la Nación (AGN).

Fondo Judicial, Serie Demandas (Fol. 92). Cartago: Archivo Histórico de Cartago, (AHC).

Borrero Guerra, Camilo. (1888). Ensayo de estadística general del Departamento de Antioquia. Medellín: Imprenta del Departamento.

Von Schenck, Fr. (1953). Viajes por Antioquia en el año de 1880. Bogotá: Publicaciones del Banco de la República.

\section{Fuentes bibliográficas}

Bushnell, David. (1984). El Régimen de Santander en la Gran Colombia. Bogotá: El Áncora Editores.

Cadena Corrales, Olga. (1988). Procesos de colonización en el Quindío: el caso de Burila. Tesis de postgrado en Historia. Universidad Nacional de Colombia, Bogotá, Colombia.

Cadena Corrales, Olga. (1997, Diciembre). "Impacto de la compañía Burila en el Quindío". En Voces, Revista de estudios sociales, № 3.

Carrero Delgado, Wilder A. (2007). Conflictos y colonización en el norte del Valle, el caso de Sevilla y la empresa Burila (1903-1930). Tesis pregrado en Historia. Universidad del Valle, Cali, Colombia.

Christie, Keith. (1986). Oligarcas, campesinos y política en Colombia. Bogotá: Editorial Universidad Nacional de Colombia. 
Kalmanovitz Salomón (editor). (2010). Nueva Historia económica de Colombia. Bogotá: Editorial Taurus y Universidad Jorge Tadeo Lozano.

Londoño, Jaime Eduardo. (2003). "Lisandro Caicedo: un empresario territorial caucano". En: Dávila L. de Guevara, Carlos (Comp.). Empresas y empresarios en la historia de Colombia. Siglos XIX - XX. Una colección de estudios recientes. Tomo I. Cali: Ediciones Uniandes, - Grupo editorial Norma.

Parsons, James. (1997). La colonización antioqueña en el occidente de Colombia. Bogotá: El Áncora Editores y Banco de la República.

Revista Semana. Recuperado el , Sábado 10 del 2010, en: http://www.semana.com/noticias-nacion/juicio-historia/142453.aspx

Safford, Frank y Palacios, Marco. (2002). Colombia, País fragmentado sociedad dividida, su historia. Bogotá: Editorial Norma.

Safford, Frank. (1977). Aspectos del siglo XIX en Colombia. Medellín: Ediciones Hombre Nuevo.

Serje, Margarita. (2005). El revés de la Nación, territorios salvajes, fronteras y tierras de nadie. Bogotá: Ediciones Uniandes-Ceso.

Tobasuña, Isaías. (2007, septiembre). "Del altiplano cundiboyacense al páramo de letras (caldas). Algunos aspectos socioculturales del proceso". En: Ponencia II Simposio Colombiano de Historia local y regional. Pereira.

Valencia Llano, Alonso. (1993). Empresarios y políticos en el Estado Soberano del Cauca. Cali: Editorial Universidad del Valle.

Vélez Rendón, Juan Carlos. (2002). Los pueblos allende el río Cauca, la formación del suroeste y la cohesión del espacio en Antioquia, 1830-1875. Medellín: Editorial Universidad de Antioquia.

Zuluaga Gómez, Víctor. (2007, septiembre). "Colonización y Guerra en el Quindío". En: Ponencia II Simposio Colombiano de Historia local y regional. Pereira.

www.lablaa.org/blaavirtual/historia/latierra/libro6-4.htm

Recibido: 20 de mayo de 2010.

Aprobado: 18 de noviembre de 2010. 
